\section{Digital nature}

MULTIMEDIA systems provide the opportunity for children to hear sounds of habitats and animals they will never experience. Dorling Kindersley's Eyewitness Encyclopedia for Nature (£59, £49.95), an "essential multimedia reference guide to the natural world", is sumptuously produced and packaged, but curiously unsatisfying. It scorned my CD-ROM drive for not having a sound card, despite not really needing one to work. The sound is a nice addition, but why does the slightly annoying American accented (and I am an American!) voice-over tediously read the simple text yet remain silent when complex Latin names appear? The small errors similar to those in other Eyewitness publications on which the CDROM is based will be noticed only by someone with prior knowledge of the subject, but are nevertheless irritating. It would have been easy to get it right for the CD-ROM package and very much worth the effort - so why wasn't it done? The habitat windows and video footage are more fun, and here sound is in fact useful: a child can hear a scarlet macaw call, learn about leaf-cutter ants or just listen to

packaged and presented books about the natural world. Meanwhile, scientists working with whole organisms and in the disciplines of taxonomy, systematics and to a certain extent evolution are becoming fewer and fewer. Could part of the problem be the persistent message of pretty pictures and lots of facts, but little science, that is so often put across by chil- the sounds of the Australian bush. Getting around each window is slow, and will frustrate all but the most computerfanatical child.

How Animals Move (Maris; $\$ 49.95, £ 39.99$ ) is an example of just how good CD-ROM software can be. It is clearly designed as a learning tool rather than an educational computer game. Each movement type is accompanied by video footage, text and hypertext crossreferencing. There are games, but they all teach a child about the presentation of scientific data as well as the principles of animal movement. The text by R. McNeill Alexander, a world authority on biomechanics, has a depth and clarity that only a real expert can bring to a subject. Scientists can write for children, and when they do, the product is often worthwhile and exciting. How Animals Move is apparently designed for older, perhaps secondary school or early undergraduate, students, but the sight of two eight-yearolds discussing the effects of viscosity and drag while using it brings home its universal appeal and amazing teaching quality. The standard set by this software will be hard to beat.

S. K.

dren's books about nature? If so, perhaps we natural scientists need to get out there and write the books (and CDs) to engage and stimulate our own replacements.

Sandra Knapp, the mother of a four-, a sixand an eight-year-old, is in the Department of Botany, Natural History Museum, Cromwell Road, London SW7 5BD, UK.

\title{
PALAEONTOLOGY
}

\section{Fossils for the next generation}

\section{Douglas Palmer}

I AM not sure whether today's computer kids still read books, let alone those about fossils other than dinosaurs. But one thing I am sure about is that they expect good graphics. I have tested a small selection of new books on two children, 12-year-old Amy and 13-year-old Ben.

Two general palaeontological texts on 'Life, the Universe and Almost Everything from Planet Earth to Parental Care' are stylistically as different as one can get. With a title like Planet Ocean: A Story of Life, the Sea, and Dancing to the Fossil Record (Ten Speed Press, \$29.95), one can guess where the authors Brad Matsen and Ray Troll originate from. The text and cartoon-style paintings confirm one's expectations. Never mind what the kids think, I like its blast of slightly wacky, Brautiganstyle post-hippy, up-beat American enthusiasm for the story of fossils, the palaeontologists who find them and their ideas. The fossil record comes across, not unreasonably, as one big lucky dip. After all, it is difficult not to wonder, sometimes with awe but more often than not with amusement, at some of the organisms that turn up: look at Hallucigenia and Wiwaxia. Perhaps God was joking. These authors are not: this is a work of deep interest and concern by real sysers amateurs in the word. Amy though. the pictures were "sweet" but Ben 60 was unimpressed. The text is accessible to some extent for 9 -year-olds but be prepared to answer a lot of questions.
David Norman's Prehistoric Life: The Rise of Vertebrates (Boxtree, £14.99) is much more strait-laced. This is a generally well-informed text, detailed and up to date. Ben was greatly taken by John Sibbick's fine paintings and drawings ("Look at the detail - how does he do it?"), as well as by the numerous photographs. As a sequel to the author's Dinosaur!, this is a useful volume and I particularly like the questioning and open-minded approach. So much of palaeontology is like an under-baked loaf: in need of proving but with bits that are overdone. The book is suitable for teenagers but younger 'dino-mites' may need some help.

The topic of The First Humans by Herbert Thomas (Thames and Hudson, £6.95) has in the past been one of those overdone bits of palaeontology, where impressive houses of cards have been built on an insecure foundations. And, as readers of Nature know well, important new discoveries and ideas on early human evolution appear every few months. But the predominantly historical approach taken by this little book means that most of it is up to date. The historical illustrations are especially appealing, ranging from engravings of Genesis from the 1732 Scheuchzer Bible to grainy photographs of the Anti-Evolution League in mid-1920s Tennessee and the notorious Scopes trial. This book, like others in the New Horizons series, is, I suspect, aimed more at interested adults than at children.

Not so Deborah Heiligman's Mary Leakey (W. H. Freeman, \$5.95, £2.95). Amy devoured this biography in one go and enthusiastically related Leakey's remarkable life story practically verbatim - although I wonder whether Leakey's success as a putative role model has as much to do with her reported hatred of school as with her fascination with human ancestry. With very traditional charcoal drawings, the book is, like a good folk tale, full of difficulties overcome. Clearly a hit, even though it is primarily aimed at 8-11-year-olds.

Meanwhile, back on the range in Texas, Louis Jacobs's Lone Star Dinosaurs (Texas A\&M University Press, \$27.95) tells a homely American family tale of hard work and togetherness in the search for and discovery of dinosaurs - not the experience of Mary Leakey's youngest son Philip, who, according to Heiligman, complained "all I get at home is stones and bones". Nevertheless, the potential thrill of finding fossil dinosaurs or hominids certainly appeals to my young readers, but being British they know they have little hope of realizing it: "Where would we get the money from?"

Douglas Palmer, a freelance science writer, is at 31 Mawson Road, Cambridge CB1 $2 D Z$, UK. 